neurological illness such as cerebrovascular disease are so low. Although there is very considerable variation in referral rates from different general practitioners, ${ }^{1011}$ it seems probable that referral rates to neurologists in the UK reflect consultant availability rather than need. Equally, the ready availability of neurologists in the US, where the number per million population is already nine times higher, and where it is suggested that many more are needed, ${ }^{5}$ indicates that many US neurologists are providing care that in the UK is provided by a family doctor. There are as yet few measures of clinical outcome, other than mortality, that can measure the impact of care upon the outcome of many disabling illnesses. Research should be undertaken to measure the increment in quality of care provided by neurologists over and above that provided by primary care physicians.

\section{References}

1 Studies on Medical and Population Subjects No 14, Vols 1-3. London: HMSO, 1958.

2 Office of Population Censuses and Surveys, Royal College of General Practitioners, Department of Health and Social Security. Morbidity statistics from general practice: second national study 1970-1971. London: HMSO, 1974.

3 Royal College of General Practitioners and Office of Population Censuses and Surveys. Department of Health and Social Security. 1981-1982. Morbidity statistics from general practice. London: HMSO, 1986.

4 Papapetropoulos T, Tsibre E, Pelekoudas V. The neurological content of general practice. $J$ Neurol Neurosurg Psychiatry 1989;52:434-5.

5 Hopkins A, Menken M, DeFriese G. A record of patient encounters in neurological practice in the United Kingdom. J Neurol Neurosurg Psychiatry 1989;52:436-8.

6 Murray TJ. Concepts in undergraduate neurological teaching. Clin Neurol Neurosurg 1976;79:275-84.

7 Marsland DW, Wood M, Mayo I. The content of family practice. J Fam Pract 1976;3:23-74.

8 Miller JR. The neurologic content of family practice. Implications for neurologists. Arch Neurol 1986; 43:286-8.

9 Eisenberg JM. The internist as gatekeeper. Ann Int Med 1985;102:537-42.

10 Walkin O, Smith AG. Variation in general practitioners' referral rate to consultants. J Royal Coll Gen Pract 1987;37:350-3.

11 Crombie DL, Fleming DM. General practitioner referrals to hospital: the financial implications of variability. Health Trends 1988;20:53-6.

\title{
Cobb's views on functional and organic illness
}

Physicians still tenaciously cling to the old dichotomy of two categories of illness: functional and organic. Professor Stanley Cobb, Bullard Professor of Neuropathology at Harvard, who preceded Raymond Adams, expatiated eloquently on this topic in his model introductory book, now sadly neglected by many students of Neurology.

"The term 'functional' is frequently misused to mean 'psychogenic.' This is a barbarism of the clinic, but has become almost routine out-patient slang. 'Functional' is a useful word in physiology and architecture. It should not be spoiled by other less acceptable usages. 'Organic' is used in a hazy way to mean that since 'organs' are involved there is something 'really wrong.' More specifically the users of 'organic' usually mean in psychiatry that there is a lesion of the brain. ('Lesion' being a visible abnormality.) If they mean this, why not say definitely what organ is meant and speak of 'cerebral lesions'? . .

In a provocative fashion which would not please all modern philosophical concepts of the brain-mind relationship he averred:

"1. No biological process goes on without change in structure;

2. Wherever the brain functions there is organic change;

3. The brain is the organ of the mind.

If we accept these three we must admit that 'organic' change takes place whenever a person has a thought. This is an important function of the brain. All function is organic, so the slang use of the term 'organic' or 'functional' is meaningless. If a line is drawn arbitrarily, its position is ordained by the point to which technology has advanced in the year. . In other words, the line between 'organic' and 'functional' (and between physical and mental is an artefact."

JMS PEARCE

Reference

Cobb S. Foundations of Neuropsychiatry. 6th edn. Baltimore, Williams \& Wilkins Co, 1958. 124-7. 